\title{
The Major Causes of Flexible Pavement Deterioration and Propose Its Remedial Measures: A Case Study Bako to Gedo Road, Oromia Region, Ethiopia
}

\author{
Shiferaw Garoma Wayessa, Dessalegn Geleta Abuye \\ Civil Engineering Department, College of Engineering and Techechnology, Wollega University, Nekemte, Oromiya, Ethiopia \\ Email address: \\ shiferawgrama77@gmail.com (S. G. Wayessa), dasssu712gelea $a$ gmail.com (D. G. Abuye)

\section{To cite this article:} \\ Shiferaw Garoma Wayessa, Dessalegn Geleta Abuye. The Major Causes of Flexible Pavement Deterioration and Propose Its Remedial \\ Measures: A Case Study Bako to Gedo Road, Oromia Region, Ethiopia. American Journal of Engineering and Technology Management. \\ Vol. 4, No. 1, 2019, pp. 10-24. doi: 10.11648/j.ajetm.20190401.13
}

Received: January 28, 2019; Accepted: March 14, 2019; Published: April 9, 2019

\begin{abstract}
Flexible pavement roads in Ethiopia often deteriorate in different ways, because of the harsh climatic conditions, lack of proper design and quality control, sudden increasing of traffic due to the construction of different industries, high loads and inadequate assessment for identifying causes of deteriorate before carrying out Maintenance and Rehabilitation. A possible remedial measures had been organized for every observed failure or deterioration to obtain normal pavement condition of the study area. An investigation was made by using laboratory and field test to determine the adequacy of the underlain material to serve as a subgrade, sub base course and base course for road construction based on project specifications and Ethiopian Road Authority (ERA) Specification. The investigation covered field tests to determine the in-situ condition of the road materials while laboratory tests on representative samples were extracted from site to determine the engineering properties of soil materials and to compare test results with the existing conditions of pavement layers. From the field tests and laboratory tests carried out, it is observed that the causes of flexible pavement deterioration of this road section are mainly due to the inadequacy of existing thickness of the base layer for the current traffic loading, overloading, engineering properties of the pavement layers material, poor method of construction, poor design quality and lack of side drainage. To reduce these causes, use boulder rocks at subbase course, reconstruction the base and providing proper drainage for the deteriorated sections must be required to reduce more damage of the flexible pavement the road section. Raveling, pumping, potholes, edge cracking and rutting are the most dominant type of deteriorations constituting more than $27 \%$ of the deterioration densities along Bako-Gedo road section.
\end{abstract}

Keywords: Flexible Pavement, Road Deterioration, Remedial Measures, Laboratory Test Results

\section{Introduction}

A road pavement is a structure of superimposed layers of selected and processed materials that are placed on the basement soil or subgrade. Flexible pavements constructed for heavy vehicles are composed of asphaltic layers (wearing, binder and base courses) and sound sub base layer which laid over a well compacted and strong subgrade foundation. Roads have helped in developing economic, cultural and social among the people by transporting them from one corner to the other corner of the country.

A flexible pavement is one of the largest infrastructure components in civil construction works and complex system that involves multiple layers of different materials subjected to various combinations of irregular traffic loadings and varying environmental conditions. It provides the road-user a smooth, quiet and skid-resistant riding surface, maximizes tire contact by providing more traction, and saves wear and tear on vehicles. Flexible pavements are safe, economical and most long-lasting roads that can be built very quickly thereby reducing costs due to traffic delays and save the traveling time.

If we look back to Ethiopian history and briefly try to visualize the genesis of road construction works, we note that some roads and bridges were constructed in early times [1]. Emperors during their royal trips, used to exert efforts to make the roads suitable for their trips by having forests cleared and difficult terrains leveled. Roads, in Ethiopia, are significant and potential means of transporting human and material over both short and long 
distance in the country. Roads have also helped in developing cultural and social ties among the people by transporting them from one corner to the other corner of the country.

Gedo- Bako road project was signed between the Ethiopian Roads Authority and China Highway Group Limited on 29 July 2009. The scope of works is upgrading of the existing Double Bituminous Surfaced Road to a DS3 Asphalt Concrete Road. The designed road is completed, which have a total length of 64.814 kilometers with a two lane $7-\mathrm{m}$ wide $\mathrm{AC}$ surfaced carriageway and 1.5-m SBST shoulder on either side of the carriageway in rural areas and 13 to $14-\mathrm{m}$ wide dual carriageway plus 2 to $2.5-\mathrm{m}$ wide footpath in town sections.

The Bako-Gedo road project was one of the main road projects included in the Ethiopian Government's 10 Years Road Sector Development Programmed (1997- 2007). Which was formulated to improve and expand the country's road network, and which has been accorded high priority by the Government of Ethiopia in order to stimulate growth of the economy and for the long term development of the country [2].

\subsection{Statement of the Problem}

Recently constructed roads in Ethiopia often deteriorate in different ways directly after opening to traffic because of many reasons. The deterioration, that may affect pavement roads, is fatigue cracking, potholes, corrugations, etc. These deteriorations affect the safety and riding quality on the pavement as they may lead to premature failure and traffic hazards. Identifying the causes of deterioration before carrying out maintenance and rehabilitation is very important task for wise use of resources and save country's budget.

The Road project of the Bako-Gedo road was expected that make major contribution to sustainable development of the country, in particular, the project area which is considered for the growing of agricultural land. The existing asphalt road has shown signs of distress and it could not provide efficient service throughout its projected level of traffic. It is expected that the road will improve the level of transportation services to the rural areas and to support transporting of agricultural products, distribution of inputs, improved social services and reduce vehicle operating costs.

Unfortunately, Bako-Gedo Road project is now experiencing early deterioration of the pavement and it is observable several stretches has already been deteriorated. The pavement defects may create both direct and indirect impacts to the travelling public. The direct impacts are the cost of maintenance on the deteriorated portions. Likewise, indirect impacts would greatly affect the project benefits which include reduction of vehicle operating costs, travel time to road users, access to markets, social and economic facilities and promotion of market integration between the rural and urban areas of Ethiopia in support of poverty reduction program of the government.

Many studies about causes of pavement deterioration focus on old pavement deterioration but the causes of deterioration of recently constructed pavement are equally important these days to avoid those maintenance cost and reconstruction.

Therefore the situational assessment should cover different causes and remedial measures of the recently constructed flexible asphalt pavement deterioration because these activities are not well developed in Ethiopia.

\subsection{Objective of the Research Study}

\subsubsection{General Objective}

The General Objective of this research was to investigate the major causes and remedies of the flexible asphalt pavement deterioration.

\subsubsection{Specific Objective}

To identify the type of deterioration of the road section.

To identify the engineering properties and to compare laboratory test results of the pavement layers with the Standard specifications.

To determine possible option or remedies for this deterioration of the road section

\subsection{Research Questions}

1 What are the types of deterioration of the flexible pavement of the road section?

2 What are the engineering properties of the flexible pavement layer of road section?

3 What is possible option or remedies for this deterioration of flexible pavement of the road section?

\section{Research Methodology}

\subsection{Project Typical Cross Sections}

The carriageway width of the road is $7.0-\mathrm{m}$ paved with Asphalt Concrete (AC) and 1.5-m wide shoulder of single bituminous surface treatment on each side for sections in rural areas. In the largest towns like Bako, the carriageway width is 14-m paved with AC and 2.5-m walkway single bituminous surface treatment on each side. In other smaller towns, the carriageway width is reduced to $13-\mathrm{m}$ and the walkway to $2-\mathrm{m}$ with the same type of construction as the largest town.

\subsection{Study Procedure}

The procedure utilized throughout the conduct of this research study are as follows: Reviewed related literatures on relevant areas of causes of damages and remedial measures of asphalt concrete pavement including, Asphalt overlay which includes articles, reference books, research papers, class lecture notes, project specifications, standards specifications like ERA, AASHTO and ASTM. Necessary data collection, organization, comparison and analysis were obtained, and then subsequently compared the results with preexisting literature and standard specifications. A conclusion and recommendation on remedial measure had been formulated based on the possible causes of deterioration on the asphalt pavement.

\subsection{Sampling Technique}

Purposive sampling technique was used by selecting 
particular parameters to make it sure that the parameters have certain characteristics as applied for this study. It is projected to be normally targets at particular geotechnical parameters

\subsection{Study Design}

The research study was conducted by using both experimental and analytical methods. Qualitative and quantitative study was employed in this study area. Qualitative study gives impression of the findings where a quantitative study was used to describe the numerical aspects of the research findings

\subsection{Data Collection Process}

Quantitative and qualitative data were utilized based on the necessary input parameters for the analysis by comparing with project specification and ERA manuals. Data collection process included but not limited to: -Desk study (reviewing letter correspondences, reports, design documents such as template of the road, working drawings etc.), Field visual inspection and inventory, Sampling representative samples, finally Field measurements and Laboratory tests were conducted. Sorting data was done by grouping into different comparison groups by type and level of severity. The study population by grouped were classified as low deterioration, medium deterioration and highly deteriorated. Laboratory test result, were compared with ERA Standard and project Specification.

\subsection{Pavement Condition Survey}

Condition surveys are essentially required to assess a pavement's physical distress and form the basis of a diagnosis regarding the maintenance or rehabilitation needs [3]. The main objective of the pavement condition survey for this study was to evaluate the state of the existing pavement and that of the subgrade by inspecting the physical conditions of the existing pavement. Before the commencement of the detailed pavement evaluation, the entire road length was visually assessed and an attempt was made to identify the types of distresses occurred on the road prism.

\subsection{Field Work}

Preliminary visual survey was undertaken along Gedo-Bako road rehabilitation. Field observations, Field tests and measurements were carried out and representative samples were taken to laboratory tests. Results from field tests and measurements were compared with the results from laboratory tests. Moreover, results from laboratory tests were compared with ERA Standard Specifications.

\subsection{Laboratory Tests}

The representative samples collected during detailed field investigation were brought to Nekemte branch ERCC District, and the following tests were undertaken. Atterberg Limits, Grain size Analysis, Compaction Tests and California Bearing Ratio (CBR) Tests were made to understand the general behavior of the road materials with standards.

The researcher collected samples from each test pits of the three sections for every pavement layer to perform the required laboratory tests. Representative samples were collected and labeled accordingly. Immediately after extracting samples, these were transported to the laboratory. The tests were performed according to AASHTO specification [4], [5] and ASTM following the procedures discussed on the soil mechanics laboratory manual by Braja, M. D. [6]. The necessary tests were conducted for all the samples and the summary of the results is presented in a tabulated form.

\subsection{Subgrade Soil Classification}

Soil classification is the arrangement of soils into different group in order that the soils in a particular group would have similar behavior. The method of classification used in this study was the AASHTO System. The AASHTO Classification system is useful for classifying soils for highways. The particle size analysis and the plasticity characteristics are required to classify a soil. The soils with the lowest number, A-1, is the most suitable as a highway material or subgrade. Range of liquid limit and plasticity index for soils in groups A -2, A -4, A-5, A -6 and A-7 [7] based on AASHTO Classification system.

$$
\begin{aligned}
& P I=L L-30 \\
& \text { For } A-7-5, P I<L L-30 \\
& \text { For } A-7-6, P I<L L-30
\end{aligned}
$$

\section{Results and Discussion}

\subsection{Pavement Condition Survey Results}

In order that on the extent of deterioration observed from the visual inspection would become reliable, proper identification was made to select three representative sections. These sections were categorized as section (1) (station Gedo to station Ejaji) where high deterioration (more severe) was observed, section (2) (station Ejaji to station Tibe)where medium deterioration (severe) was observed and section (3) ( station Tibe to station Bako) where observed relatively low

\begin{tabular}{|c|c|c|c|c|}
\hline Sections & Station of the section. & Test pits & Total area of deteriorated & Types of deterioration \\
\hline 1 & Station Gedo to station Ejaji & $\begin{array}{l}\text { 1. } \mathrm{Km} 130+523 \\
\text { 2. } \mathrm{Km} 130+570 \\
\text { 3. Km } 130+600\end{array}$ & & High deterioration \\
\hline 2 & station Ejaji to station Tibe & $\begin{array}{l}\text { 1. } \mathrm{Km} 102+030 \\
\text { 2. } \mathrm{Km} 102+175 \\
\text { 3. } \mathrm{Km} 102+187\end{array}$ & & Medium deterioration \\
\hline
\end{tabular}
deterioration.

Table 1. Test pit locations. 


\begin{tabular}{|c|c|c|c|c|}
\hline Sections & Station of the section. & Test pits & Total area of deteriorated & Types of deterioration \\
\hline 3 & station Tibe to station Bako & $\begin{array}{l}\text { 1. } \mathrm{Km} 76+212 \\
\text { 2. Km 76+457 } \\
\text { 3. Km 76+568 }\end{array}$ & & Low deterioration \\
\hline
\end{tabular}

Table 1 shows the locations where highly deteriorated, medium deteriorated and low deteriorated occurred for every section, three (3) test pits were extracted for each road section for laboratory tests. The road width and pavement material thickness were measured using a meter tape. In situ density was measured in the laboratory for each layer of the three sections. The following pictures show the type and extent of deterioration along the Bako-Gedo road rehabilitation project.

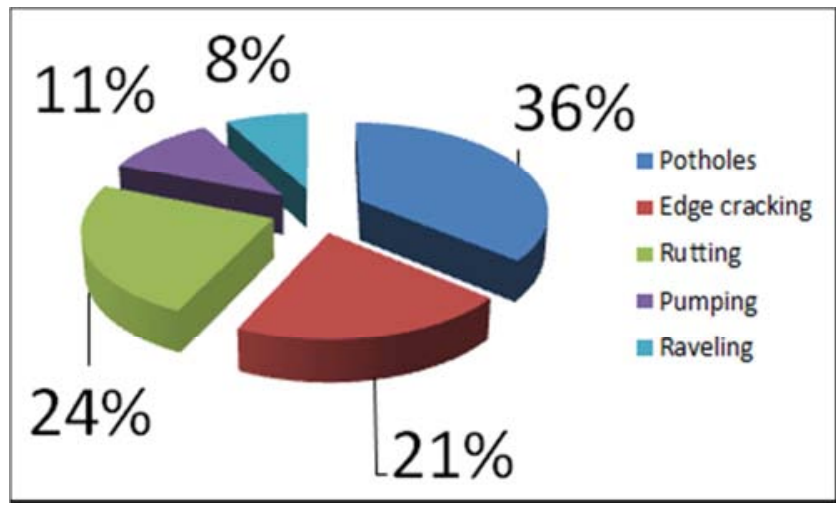

Figure 1. The percentage of common deterioration types and their severity.

The major types of deterioration observed along the study area of Bako-Gedo rehabilitation Road Project. Relative to this, the researcher had organized the possible deterioration types based on existing condition of the pavement surface together with the extent of damage and had been ranked accordingly. The following Figures show the different photos taken from the field observation of the different types of deterioration along Bako-Gedo road project.

\subsection{Field Observation and Investigation Results}

Based on field observation and investigation the width of the road is 7 meter carriageway and 1.5 meters shoulders on both sides; whereas, in town sections the roadway was provided with 3.5 meters parking lane and 1.5 meters pedestrian walkway on both sides.

The thickness of the pavement layers is listed below.

Table 2. Summary of actual pavement materials thickness.

\begin{tabular}{llll}
\hline \multirow{2}{*}{ Station } & \multicolumn{3}{l}{ Thickness of the pavement layers } \\
\cline { 2 - 4 } & $\begin{array}{l}\text { Base course } \\
\text { (GB1) }\end{array}$ & $\begin{array}{l}\text { Sub base } \\
\text { course (GS) }\end{array}$ & $\begin{array}{l}\text { Capping layer } \\
\text { (GC) }\end{array}$ \\
\hline $130+523$ & 20.0 & 25 & 28 \\
$130+570$ & 20.0 & 25 & 23 \\
$130+600$ & 20.0 & 25 & 33 \\
$102+030$ & 19.50 & 22 & 30 \\
$102+175$ & 20.00 & 25 & 26 \\
$102+187$ & 18.77 & 21 & 29 \\
$76+212$ & 19.00 & 25 & 31 \\
$76+457$ & 20.00 & 25 & 27 \\
$76+568$ & 19.60 & 25 & 36 \\
\hline
\end{tabular}

Based on the results of pavement layers measurement in the project study area, at Km Station 130+430-130+580, Km 102

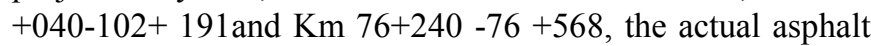
thickness as compiled the minimum design thickness of 5 centimeter in the study area.

\subsection{Field Density Test Results}

The field dry densities and the field moisture contents obtained on the subgrade, capping layer, sub base, and the base course materials are tabulated in Tables 3, 4, and 5 .

Table 3. Test results on field density of subgrade material.

\begin{tabular}{|c|c|c|c|c|}
\hline Section & Station (km) & Water Conten \% & Bulk density (g/cu.cm) & Dry density (g/cu.cm) \\
\hline \multirow{3}{*}{$\begin{array}{l}\text { Section } 1 \text {, } \\
\text { Km Station } 130+430-130+580\end{array}$} & $130+530$ & 30.7 & 2.18 & 1.48 \\
\hline & $130+580$ & 25.36 & 2.19 & 1.94 \\
\hline & Average & 28.03 & 2.19 & 1.71 \\
\hline \multirow{3}{*}{$\begin{array}{l}\text { Section 2, } \\
\text { Km Station } 102+040-102+191\end{array}$} & $102+040$ & 25.4 & 2.02 & 1.61 \\
\hline & $102+191$ & 13.5 & 2.18 & 1.93 \\
\hline & Average & 19.45 & 2.1 & 1.77 \\
\hline \multirow{2}{*}{$\begin{array}{l}\text { Section } 3 \text {, } \\
\text { Km Station } 76+240-76+568\end{array}$} & $76+240$ & 19.5 & 2.19 & 1.93 \\
\hline & Average & 26.45 & 2.01 & 1.72 \\
\hline
\end{tabular}

Table 4. Test results of field density of capping layer and natural sub base material.

\begin{tabular}{|c|c|c|c|c|c|c|c|}
\hline \multirow[b]{2}{*}{ Section } & \multirow[b]{2}{*}{ Station } & \multicolumn{3}{|c|}{ Capping layer } & \multicolumn{3}{|l|}{ Natural subbase } \\
\hline & & $\begin{array}{l}\text { Water } \\
\text { content }(\%)\end{array}$ & $\begin{array}{l}\text { Bulk density } \\
\text { (g/cu.cm) }\end{array}$ & Dry density (g/cc) & Water content $(\%)$ & $\begin{array}{l}\text { Bulk density } \\
\text { (g/cu.cm) }\end{array}$ & Dry density (g/cc) \\
\hline \multirow{4}{*}{1} & $130+523$ & 24 & 1.49 & 1.23 & 15.2 & 2.18 & 1.94 \\
\hline & $130+570$ & 23.83 & 2.20 & 1.85 & 12 & 2.16 & 2.13 \\
\hline & $130+600$ & 17.1 & 2.05 & 1.75 & 13.5 & 2.18 & 1.95 \\
\hline & Average & 21.64 & 1.91 & 1.61 & 13.56 & 2.17 & 2.00 \\
\hline \multirow{3}{*}{2} & $102+030$ & 13.5 & 2.06 & 1.82 & 15.6 & 2.13 & 1.78 \\
\hline & $102+175$ & 17.7 & 2.09 & 1.87 & 11.23 & 2.20 & 2.14 \\
\hline & $102+187$ & 13.5 & 2.09 & 1.87 & 17.6 & 2.16 & 1.62 \\
\hline
\end{tabular}




\begin{tabular}{llllllll}
\hline \multirow{3}{*}{ Section } & Station & \multicolumn{2}{l}{ Capping layer } & \multicolumn{5}{c}{ Natural subbase } \\
\cline { 3 - 8 } & & $\begin{array}{l}\text { Water } \\
\text { content (\%) }\end{array}$ & $\begin{array}{l}\text { Bulk density } \\
\text { (g/cu.cm) }\end{array}$ & Dry density (g/cc) & Water content (\%) & $\begin{array}{l}\text { Bulk density } \\
\text { (g/cu.cm) }\end{array}$ & Dry density (g/cc) \\
\cline { 2 - 8 } & Average & 14.9 & 2.08 & 1.85 & 14.81 & 2.16 & 1.87 \\
& $76+212$ & 17.7 & 2.18 & 1.97 & 23.83 & 2.00 & 1.85 \\
3 & $76+457$ & 17.7 & 2.14 & 1.83 & 14.7 & 2.18 & 1.78 \\
& $76+568$ & 13.5 & 2.00 & 1.72 & 19 & 1.99 & 1.68 \\
& Average & 16.3 & 2.11 & 1.84 & 19.17 & 2.05 & 1.77 \\
\hline
\end{tabular}

Table 5. Results of field density test of base course material.

\begin{tabular}{lllll}
\hline \multirow{2}{*}{ Section } & Station & Base course & & Dry density \\
\cline { 3 - 5 } & & Water content (\%) & Bulk density (g/cu.cm) & 1.91 \\
& $130+523$ & 3.05 & 2.16 & 2.26 \\
1 & $130+570$ & 2.24 & 2.16 & 2.23 \\
& $130+600$ & 3.40 & 2.19 & 2.13 \\
& Average & 2.9 & 2.17 & 1.76 \\
2 & $102+030$ & 5.00 & 2.14 & 2.21 \\
& $102+175$ & 4.4 & 2.21 & 1.94 \\
& $102+187$ & 2.28 & 2.16 & 2.21 \\
& Average & 3.89 & 2.17 & 1.84 \\
& $76+212$ & 2.28 & 2.23 & 1.78 \\
\end{tabular}

\subsection{Laboratory Tests}

\subsubsection{Atterberg's Limit Test Results}

The Plasticity of base course and sub base materials were found to be non-plastic and for fill and subgrade materials are tabulated below.

Table 6. Atterberg's limit of pavement materials.

\begin{tabular}{lllllll}
\hline \multicolumn{2}{l}{ Atterberg's limit of subgrade } & & & \multicolumn{3}{c}{ Atterberg's limit of selected subgrade fill material (capping) } \\
\hline Location & Liquid Limit & Plastic Limit & Plasticity Index & Liquid Limit & Plastic Limit & Plasticity Index \\
\hline $130+523$ & 56 & 30 & 26.00 & 45.2 & 30.5 & 14.6 \\
$130+570$ & 53 & 30 & 23.00 & 40.5 & 28.8 & 11.7 \\
$130+600$ & 61 & 39 & 22.00 & 43.0 & 31 & 12 \\
$102+030$ & 55.4 & 36.30 & 19.10 & 38 & 23 & 13.1 \\
$102+175$ & 63.3 & 32.00 & 31.30 & 40.9 & 27 & 4 \\
$102+187$ & 53.8 & 31.30 & 22.50 & 31 & 28 & 7 \\
$76+212$ & 64.4 & 43.00 & 21.40 & 35 & 35 & 6 \\
$76+457$ & 52.2 & 27.70 & 24.50 & 41 & 29.5 & 8.3 \\
$76+568$ & 54.8 & 35.80 & 19.00 & 37.8 & & \\
\hline
\end{tabular}

\subsubsection{Grain Size Analysis Result}

The results of grain size analysis are plotted in Figures below

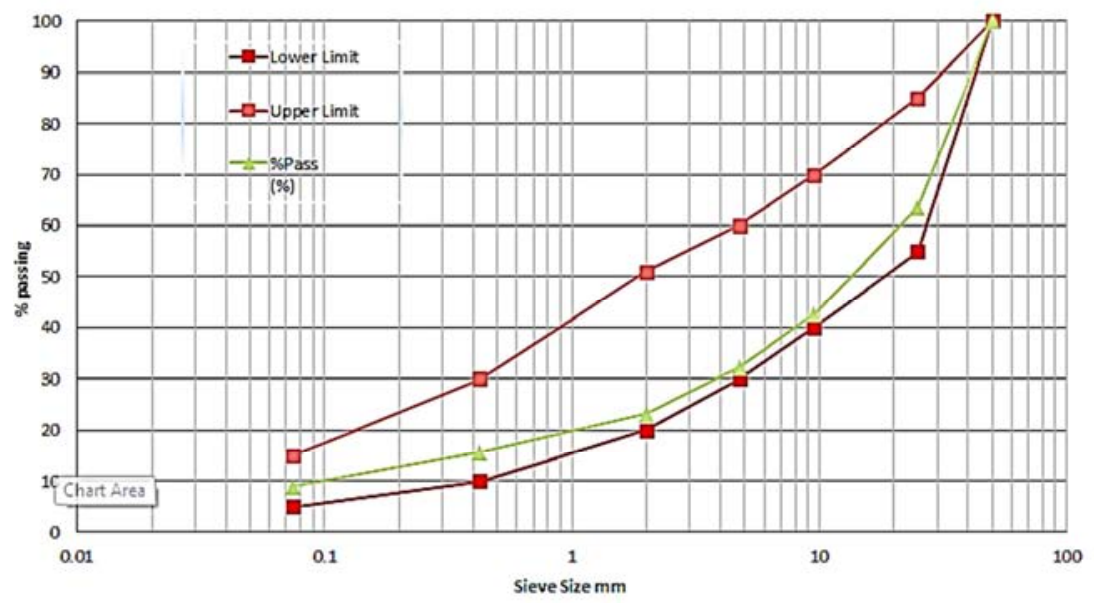

Figure 2. Base course material particle size distribution at section (1). 


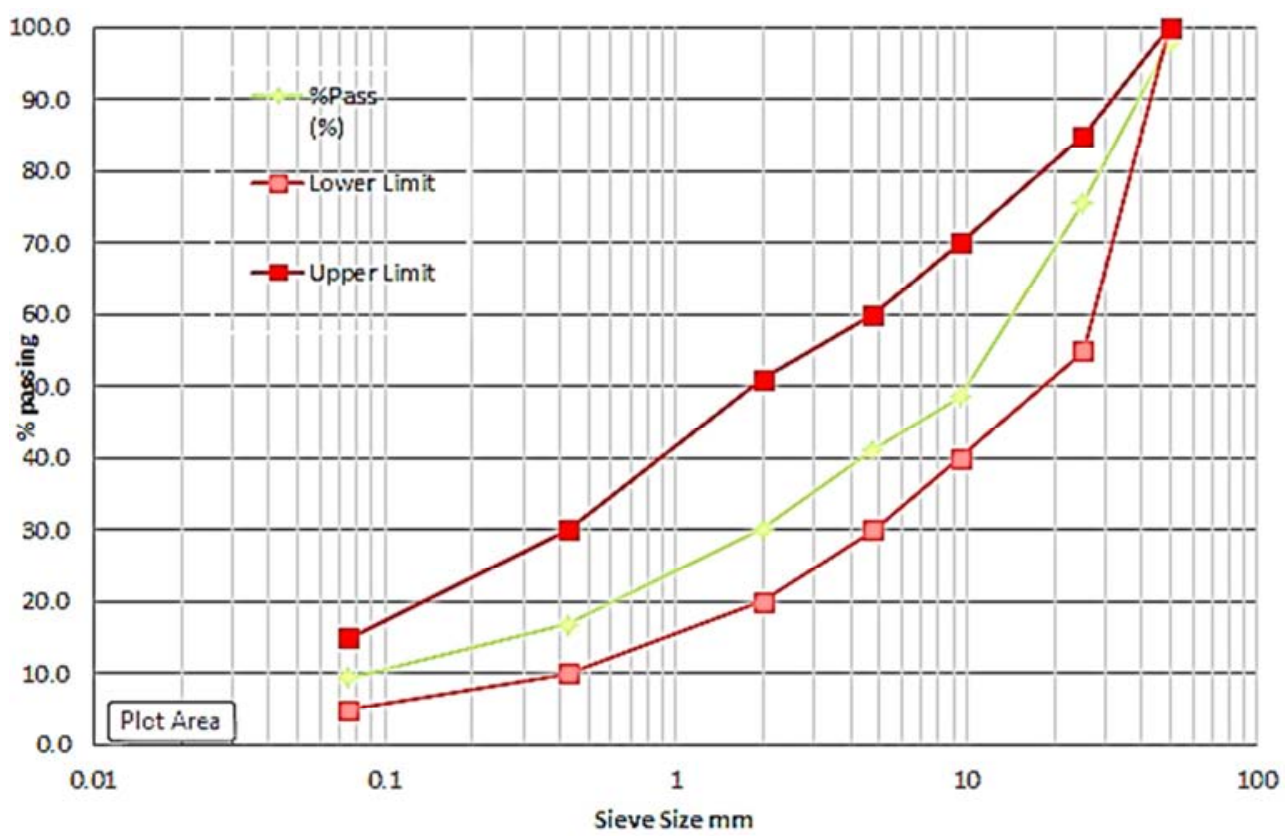

Figure 3. Base course material particle size distributions at section (2).

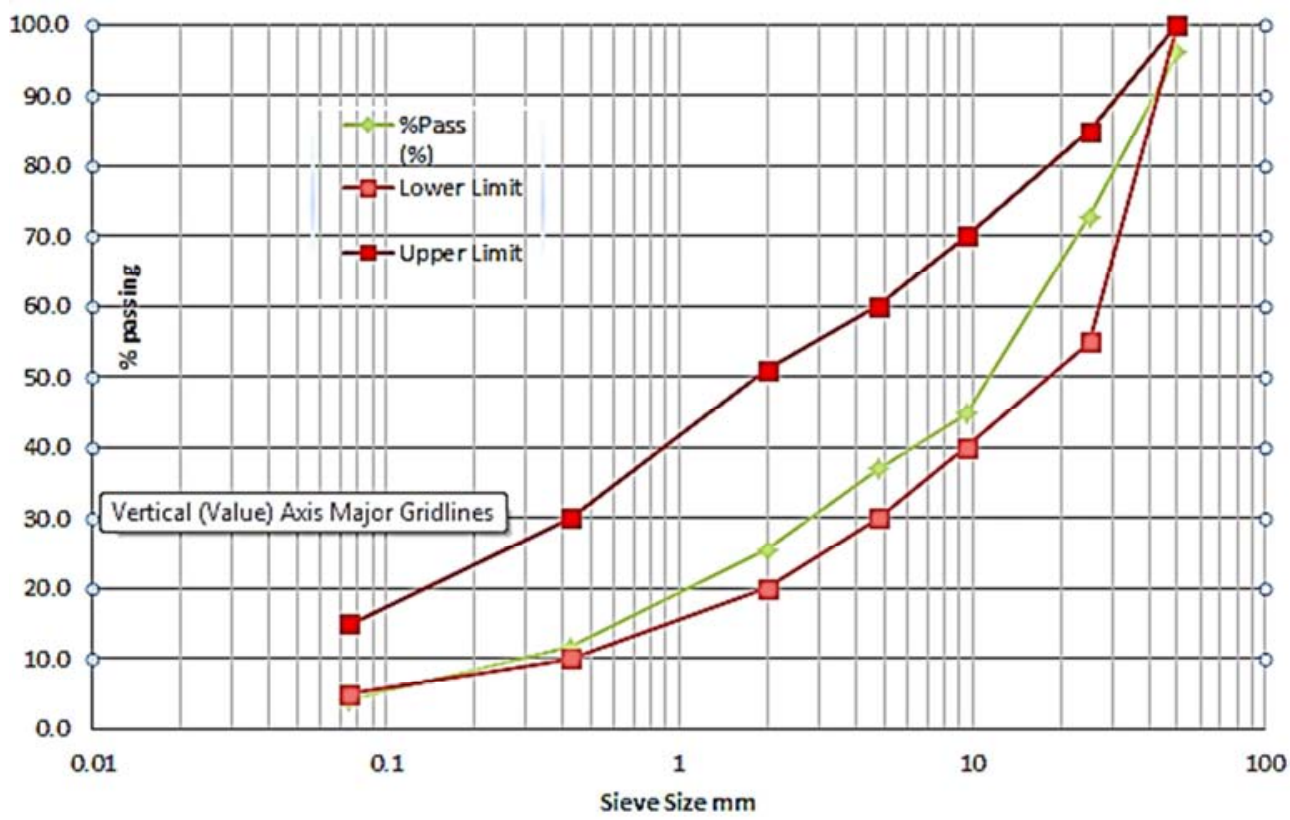

Figure 4. Base course material particle size distribution at section (3).

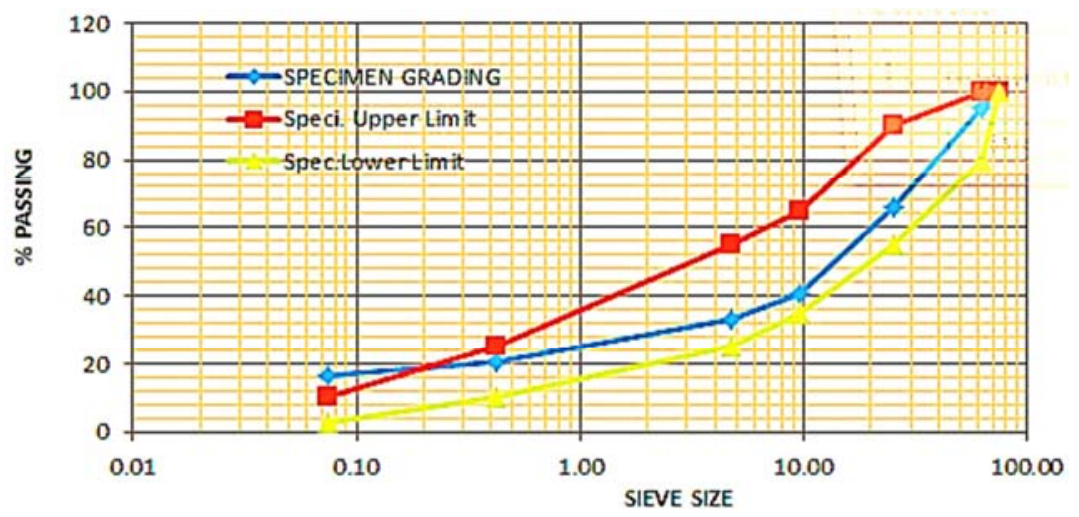

Figure 5. Natural Sub base material particle size of section (1). 


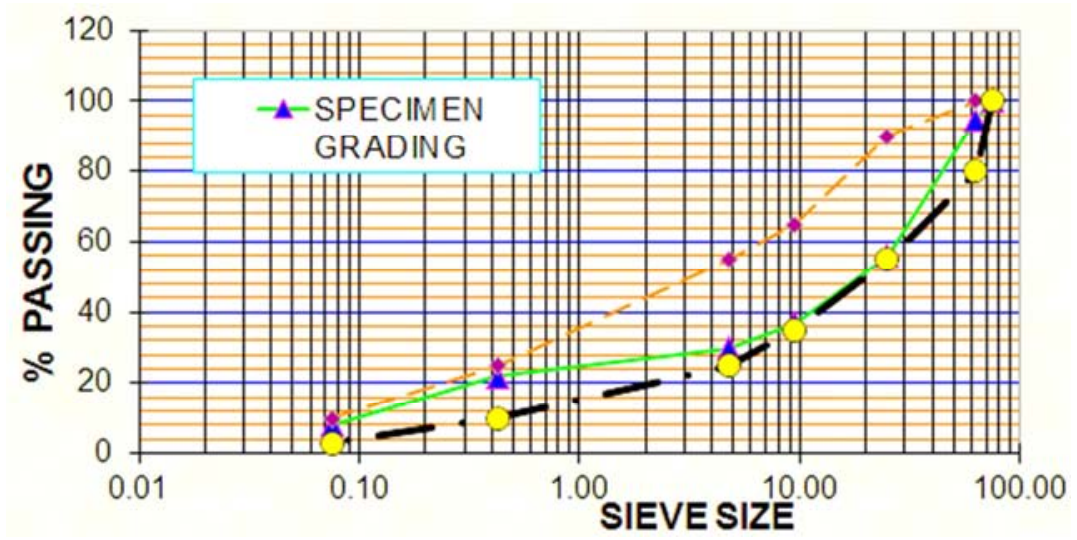

Figure 6. Natural Sub base material particle size of section (2).

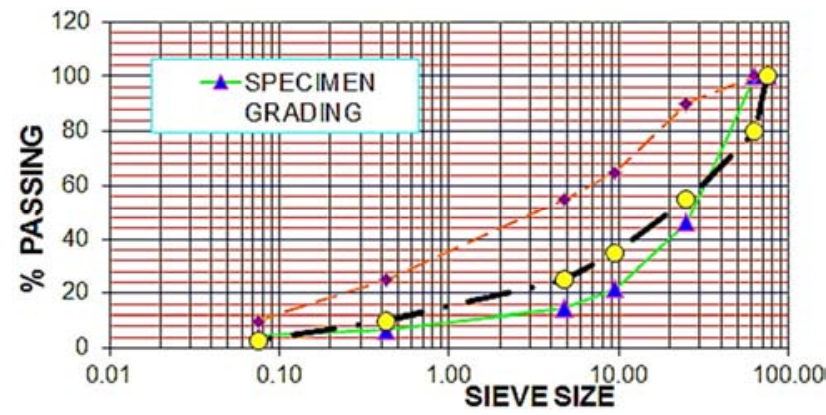

Figure 7. Natural Sub base material particle size of section (3).

\subsubsection{Moisture-density Relation (Compaction) Test}

The dry density values on the y-axis and the moisture contents on the x-axis were plotted. And a smooth curve connecting the plotted points was drawn

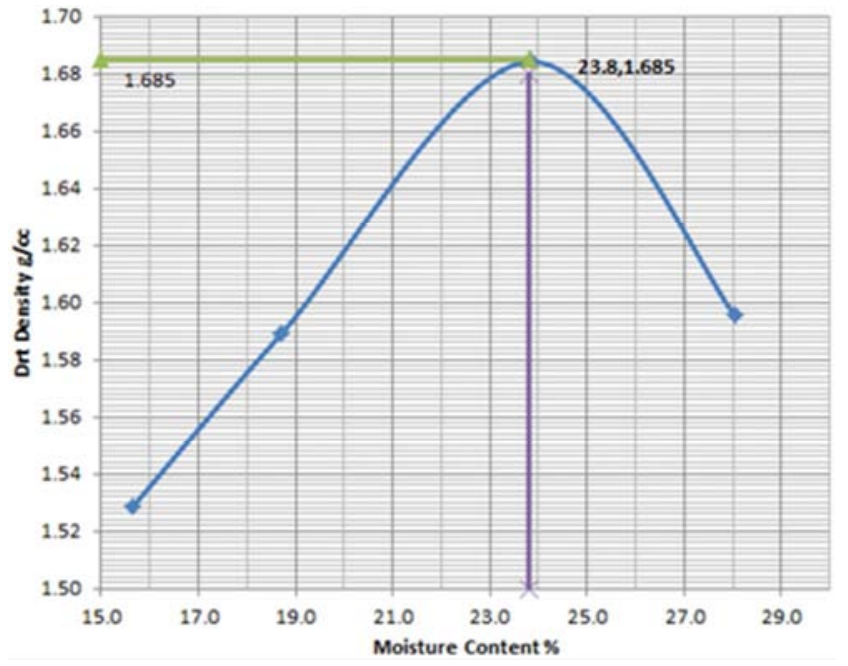

Figure 8. Moisture content against dry density.

Table 7. Laboratory compaction test of subgrade material.

\begin{tabular}{llllllllll}
\hline & Section 1 & \multicolumn{3}{c}{ Section 2 } & \multicolumn{3}{c}{ Section 3 } \\
\cline { 2 - 10 } & $\mathbf{1 3 0}+\mathbf{5 2 3}$ & $\mathbf{1 3 0}+\mathbf{5 7 0}$ & Average & $\mathbf{1 0 2}+\mathbf{0 3 0}$ & $\mathbf{1 0 2}+\mathbf{1 7 5}$ & Average & $\mathbf{7 6 + 2 1 2}$ & $\mathbf{7 6 + 4 5 7}$ & Average \\
\hline OMC & 30.75 & 17.6 & 24.18 & 25.4 & 16.72 & 21.06 & 16.7 & 25.8 & 21.25 \\
MDD & 1.48 & 1.62 & 1.55 & 1.61 & 1.83 & 1.72 & 1.74 & 1.47 & 1.605 \\
\hline
\end{tabular}

Table 8. Laboratory compaction tests of natural sub base and capping layer material.

\begin{tabular}{|c|c|c|c|c|c|}
\hline \multirow{2}{*}{ Section } & \multirow{2}{*}{ Station of test.KM } & \multicolumn{2}{|c|}{ Capping layer } & \multicolumn{2}{|c|}{ Natural sub base } \\
\hline & & OMC (\%) & MDD (g/cc) & OMC (\%) & MDD (g/cc) \\
\hline \multirow{4}{*}{1} & $130+523$ & 23.83 & 1.685 & 18.8 & 1.6 \\
\hline & $130+570$ & 24.00 & 1.690 & 14.00 & 2.15 \\
\hline & $130+600$ & 18.7 & 1.73 & 13.44 & 1.86 \\
\hline & Average & 22.17 & 1.70 & 15.41 & 1.87 \\
\hline \multirow{4}{*}{2} & $102+030$ & 11.4 & 1.84 & 11.23 & 2.14 \\
\hline & $102+175$ & 11.74 & 1.83 & 12.00 & 1.79 \\
\hline & $102+187$ & 16.83 & 1.84 & 13.5 & 1.95 \\
\hline & Average & 13.32 & 1.84 & 12.24 & 1.96 \\
\hline \multirow{4}{*}{3} & $76+212$ & 17.41 & 1.72 & 11.69 & 2.18 \\
\hline & $76+457$ & 24.18 & 1.48 & 10.87 & 2.14 \\
\hline & $76+568$ & 24.95 & 1.469 & 15.7 & 1.83 \\
\hline & Average & 22.18 & 1.56 & 12.75 & 2.05 \\
\hline
\end{tabular}


Table 9. Laboratory compaction test of base course material.

\begin{tabular}{llll}
\hline \multirow{2}{*}{ Section } & Station of test. KM & Base course & MDD (g/cc) \\
\cline { 3 - 4 } 1 & & OMC (\%) & 2.26 \\
& $130+523$ & 2.20 & 2.23 \\
& $130+570$ & 3.40 & 2.15 \\
& $130+600$ & 5.00 & 2.21 \\
& Average & 3.53 & 2.24 \\
& $102+030$ & 2.30 & 2.10 \\
& $102+175$ & 7.40 & 2.21 \\
& $102+187$ & 2.30 & 2.18 \\
& Average & 4.00 & 2.19 \\
3 & $76+212$ & 2.40 & 2.15 \\
& $76+457$ & 3.22 & 2.08 \\
& $76+568$ & 3.52 & 2.14 \\
\hline
\end{tabular}

\subsubsection{California Bearing Ratio (CBR) Test Results}

The test results from the low deterioration, medium deterioration and high deterioration of road sections are listed in Tables 10. Based on test results, the values indicate that the materials used for all the three conditions have very good CBR values when compacted at their maximum dry density and optimum moisture content except sub base materials.

Table 10. Average values of CBR test results for the three sections.

\begin{tabular}{lllll}
\hline Section & Base course & Natural Sub base & Capping layer \\
\hline Section-1 & 105.33 & 36.67 & 21.67 & \\
Section-2 & 115.00 & 29.17 & 21.23 & 5.22 \\
Section-3 & 124.0 & 43.67 & 18.20 & 5.47 \\
\hline
\end{tabular}

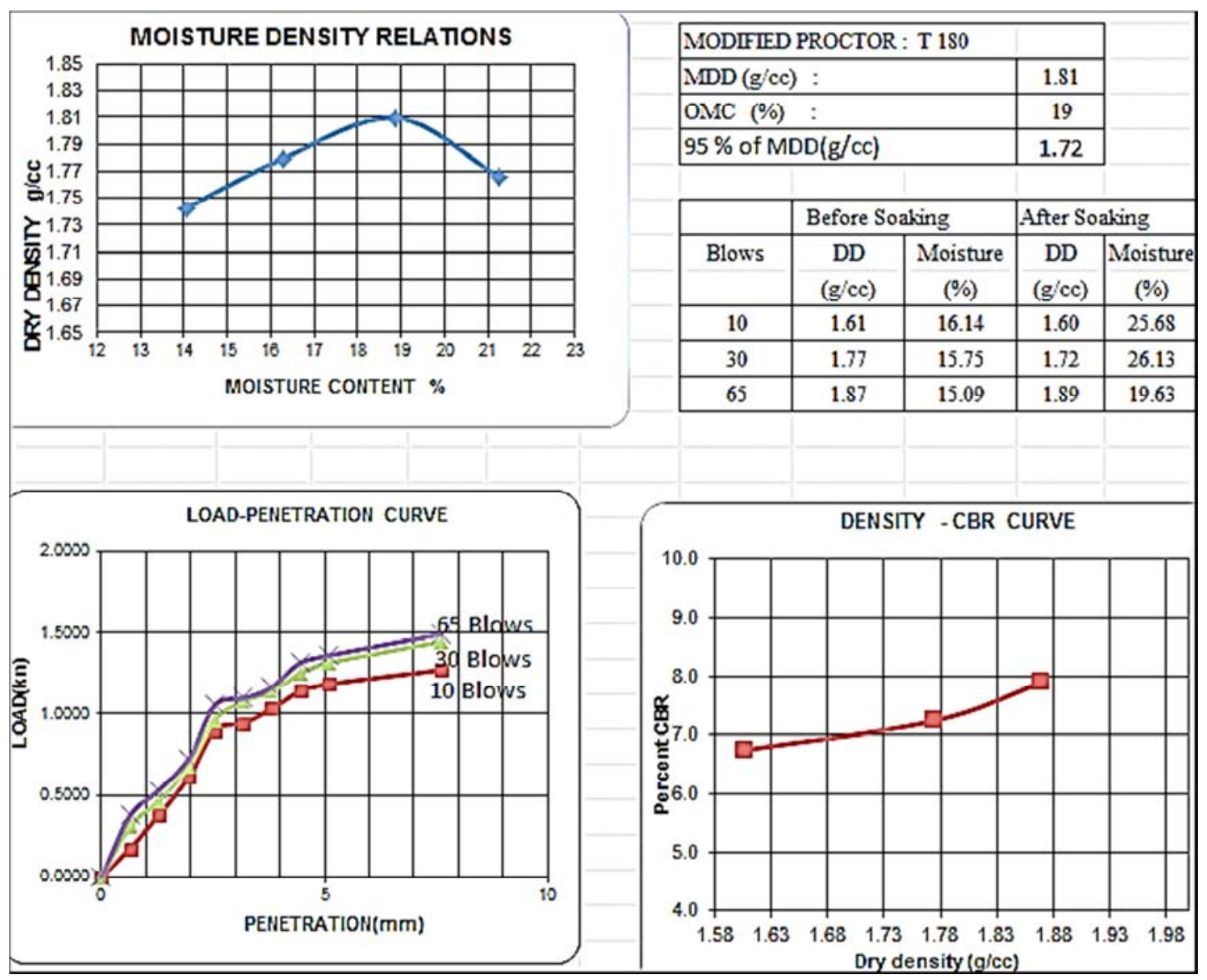

Figure 9. Stress vs. Penetration relationship for base course material.

The above figure expresses the results of the stress-penetration relationship for the subgrade materials at station KM 102+030 CBR soaked and dry density values. This section was presented to visualize the process results, while the other sections were given in Appendix. 


\subsection{Discussion}

The following comparisons and discussions are based on the interpretation of all data gathered from the study sections that had been obtained at Bako-Gedo Rehabilitation of Road Project were presented in orderly manner.

\subsubsection{Road Pavement Surface Deterioration}

The observation results show that Edge cracking, pumping, raveling, pothole and rutting types of deterioration were recognized along the selected sections. The causes of the observed deterioration could be moisture fluctuation, poor drainage facilities, and poor method of compaction as described by Keith RK. (1992). The pothole was due to the removal or disintegration of materials in weakened spots on the pavement surface. In order to evaluate the carrying capacity of the pavement materials due to the traffic loadings throughout its service design life, the following analyses were made.

From the point of view of traffic analysis and according to the ERA pavement design manual, for the traffic Class is "T5" with ESAs ranging from 3-6 million [7]. Based on project design data of the study area, it comprised of about 5.5 Million Cumulative Standard Axle for the design period. This means that the project design data was within the class "T5" [4].

The thickness of each layer is a function of the Equivalent standard Axles (ESAs) and the CBR of the subgrade layer. For the CBR test, the subgrade strength class was classified as S3 with CBR range of 5-7 [7]. According to TRL Road Note 31 Chart 1 [1], the thickness of the base course aggregates and sub base course for traffic class T5 with corresponding ESAs ranging from 3.0-6.0 million must be $20 \mathrm{~cm}$ thick and $25 \mathrm{~cm}$ thick respectively. From Table 2, it can be seen that the average thickness of the base course aggregates at section (1) is $20 \mathrm{~cm}$, at section (2) is $19.42 \mathrm{~cm}$, and the average thickness of natural sub base course at (2) and (3) is less than $25 \mathrm{~cm}$. This indicates that the base course at section (2) and section (3) are less than the minimum thickness of $20 \mathrm{~cm}$ and the sub base course of the section (2) section (3) are also less than the minimum thickness of $25 \mathrm{~cm}$, so except base course at section (1) and sub base at section (1) would not be able to carry the traffic loads throughout its service life based on the requirements of standard specification.

On the other hand, the base course and sub base course at section (1) showed that it would be able to carry the traffic loads throughout its service life because it is equal to the minimum required thickness as per approved plan of the project.

\subsubsection{Traffic Volume}

Road surfaces often wear under the action of traffic, particularly during the very early life of the road. However the action of traffic continues to wear the surface texture and thus gradually reduces the high speed skidding resistance, [8]. Traffic volume and size contributes to road safety and conditions. Recognizing of vehicles' volume and sizes (industrial transportations) is the key for decreasing road deterioration. The composition of the individual vehicles per category in the project road count sections for Bako-Gedo presented here under and observed the traffic volume and types of the vehicles are determined Table 6 and 7. There are two types of vehicles category on this road section currently.

A Passenger vehicle category

The Passenger vehicle category includes Car, S/Wagon\& pickup, small Bus and Large buses. The percentage composition of passenger vehicle category estimated about $1 \%, 19 \%, 12 \%$ and $6 \%$ respectively of total traffic on the project road section. Higher percentage of Station wagon observed dominantly.

B Freight vehicle category

The Freight vehicle category includes small Truck, Medium Truck, heavy trucks and truck \&Trailer. The percentage composition of the Freight vehicle category estimated about $1 \%, 27 \%, 23 \%$, and $12 \%$ respectively. Higher percentage of medium trucks observed dominantly and used for transporting goods at different town along the project. So recognizing of vehicles' volume and sizes or category is the key for decreasing road deterioration. As, observed the composition of the individual vehicles per category and volume on the Bako-Nekemte road section currently not changed as per design project specifications.

\subsubsection{Compaction Test}

The subgrade material had been evaluated and it can be observed from Table 11 that there was increased of about $1.85 \%$ at section (1) and decrease $0.4 \%$ at section (2) and an increase of $1.8 \%$ at section 33 (3) on moisture content at the field than the optimum moisture content obtained in the laboratory. The increased of the moisture content at section (1) was mainly due to percolation of ground water through the cracks and potholes and at section (3) due to poor drainage during the rainy season on the road surface. Aside from this, it was observed that the main cause of the deterioration of these road sections which was known to have seepage of the water within the embankment. This will resulted decrease in dry density. The compaction at sections (1) and section (3) were relatively not good because of this decreased dry density. Hence these finding indicates that the subgrade material at section (1) and section (3) consisted of less at the required dry density as per the standard specification. Based on the ERA Pavement Design Manual [4], it is recommended that the top $25 \mathrm{~cm}$ of all subgrades should be compacted to a relative density of at least $95 \%$ of the maximum dry density achieved by heavy compaction. Likewise section (2) is greater than this required specification.

Based on the sample conducted, it was found out that the selected material used as a capping layer or selected subgrade fill material at sections (1), (2) and (3) were fine grained soils. At section (1), the average MDD for the selected capping material was $1.70 \mathrm{gm}$. /cc, but the average of MDD of field result of section (1) of this material is $1.90 \mathrm{gm} . / \mathrm{cc}$. In comparison percentage of compaction the MDD is $93.21 \%$ to $95.79 \%$ which was less than the required of $95 \%$ based on specification. The average OMC for the selected material was 
$22.17 \%$ and the range of moisture content that was found during field test had been recorded between $17.1 \%$ and $24.00 \%$ or averagely 21.64 which is greater than the OMC.

The selected material used for medium deterioration road at section (2) had an average MDD of $1.96 \mathrm{gm} . / \mathrm{cc}$ and an average $\mathrm{OMC}$ of $13.42 \%$. The field test results for the dry density and moisture content were in the range of $1.82 \mathrm{gm} / \mathrm{cc}$ to $1.87 \mathrm{gm}$. $/ \mathrm{cc},(1.85 \mathrm{gm}$. $/ \mathrm{cc})$ and $13.50 \%$ to $17.7 \%, 14.9 \%$ respectively. From these results, it was seen that the percentage of compaction ranges from $96.56 \%$ to $98.78 \%$, which was greater than the required and the moisture content was nearly equal to the OMC.

At section (3), the field moisture content was $18.3 \%$ and MDD was $1.84 \mathrm{gm}$. /cc averagely. The average OMC and MDD for the selected material of the section (3) were $19.17 \%$ and 1.77 respectively. From these results, it was found out that the percentage of compaction ranges from $97.35 \%$ to $100.00 \%$ which was greater than the required of $95 \%$ based on specification.

The natural sub-base material for the highly deteriorated road section at section (1) had an average OMC of $15.41 \%$ and an average MDD of $1.87 \mathrm{gm} / \mathrm{cc}$. The field dry density observed $2.00 \mathrm{gm} / \mathrm{cc}$ while the moisture content was $15.56 \%$. It was found that the average in moisture content is equal in both field and laboratory by using given tolerance $-2 \%$ or $+2 \%$ of OMC [9]. Because of this result the percentage of compaction had found in the range $95.70 \%$ to $96.80 \%$ which was greater than the required of $95 \%$ based on specification.

The average optimum moisture content observed during the laboratory test results for natural sub base course of medium deterioration road section (2) was $12.24 \%$, while the average of the field density test results was $12.81 \%$. The field result of moisture content is much higher than the OMC. Likewise, the average MDD result, was found to have $1.96 \mathrm{gm} . / \mathrm{cc}$, during laboratory test, on the other hand, the average values found in the field test is $1.87 \mathrm{gm} / \mathrm{cc}$ and the percent compaction was observed from $95.56 \%$ to $97.76 \%$, relatively which is greater than the specified requirements.

The field moisture test results for section (3), the subbase material represented value averagely $17.17 \%$ while the average OMC found from laboratory test results was $12.75 \%$. The specification tolerance for moisture content is $+/-2 \%$ of OMC [9]. This study showed that the value is out of the tolerance based on standard specifications. The average MDD for the natural subbase material is $2.05 \mathrm{gm}$./cc. The results had been found in the field $1.77 \mathrm{gm}$. /cc averagely. Because of this result the percentage of compaction ranges from $91.44 \%$ to $94.63 \%$. These values are below the standard specification which requires at least $95 \%$ of the maximum compaction.

The field moisture content of the base course material as shown in Table 9 is $2.50 \%$ less than the optimum moisture content obtained in the laboratory $3.04 \%$ averagely by using given tolerance at sections (3). The average decrease in moisture is $0.540 \%$ at section (3), but the field moisture content of the base course materials at sections (1) and (2) are respectively $2.90 \%$ and $3.89 \%$ averagely, while the moisture content obtained in the laboratory test of section (1) and (2) are respectively $3.53 \%$ and $4.00 \%$ which is below the optimum moisture content obtained in the laboratory. The field dry density at all sections are ranges from $98.56 \%$ to $101.78 \%$, which is greater than the requirements set in the standard specification which is comparatively greater than $98 \%$.

Table 11. Comparison of field density and laboratory compaction test of subgrade material.

\begin{tabular}{|c|c|c|c|c|}
\hline \multirow{2}{*}{ Station $(\mathbf{K m})$} & \multicolumn{2}{|l|}{ Field test } & \multicolumn{2}{|c|}{ Laboratory test } \\
\hline & Water content (\%) & Dry density $\left(\mathrm{g} / \mathrm{cm}^{3}\right)$ & OMC (\%) & $\operatorname{MDD}\left(\mathrm{g} / \mathrm{cm}^{3}\right)$ \\
\hline $130+523$ & 30.7 & 2.18 & 30.75 & 1.48 \\
\hline $130+580$ & 25.36 & 2.19 & 17.6 & 1.62 \\
\hline Average & 28.03 & 1.71 & 24.18 & 1.55 \\
\hline $102+030$ & 25.4 & 1.61 & 25.40 & 1.61 \\
\hline $102+191$ & 13.5 & 1.93 & 16.72 & 1.83 \\
\hline Average & 19.45 & 1.77 & 21.06 & 1.72 \\
\hline $76+568$ & 21.4 & 1.51 & 25.80 & 1.47 \\
\hline Average & 17.45 & 1.72 & 21.25 & 1.61 \\
\hline
\end{tabular}

Table 12. Comparison of field density and laboratory compaction test of capping material.

\begin{tabular}{|c|c|c|c|c|c|}
\hline \multirow{2}{*}{ Catagory } & \multirow{2}{*}{ Station } & \multicolumn{2}{|l|}{ Field test } & \multicolumn{2}{|c|}{ Laboratory test } \\
\hline & & Water content $(\%)$ & Dry density (g/cc) & OMC (\%) & MDD (g/cm3) \\
\hline \multirow{4}{*}{1} & $130+523$ & 24 & 1.23 & 23.83 & 1.685 \\
\hline & $130+570$ & 23.83 & 1.85 & 24.00 & 1.690 \\
\hline & $130+600$ & 17.1 & 1.75 & 18.7 & 1.73 \\
\hline & Average & 21.64 & 1.61 & 22.17 & 1.70 \\
\hline \multirow{4}{*}{2} & $102+030$ & 13.5 & 1.82 & 11.4 & 1.84 \\
\hline & $102+175$ & 17.7 & 1.87 & 11.74 & 1.83 \\
\hline & $102+187$ & 13.5 & 1.87 & 16.83 & 1.84 \\
\hline & Average & 14.9 & 1.85 & 13.32 & 1.84 \\
\hline \multirow{4}{*}{3} & $76+212$ & 17.7 & 1.97 & 17.41 & 1.72 \\
\hline & $76+457$ & 17.7 & 1.83 & 24.18 & 1.48 \\
\hline & $76+568$ & 13.5 & 1.72 & 24.95 & 1.469 \\
\hline & Average & 16.3 & 1.84 & 22.18 & 1.56 \\
\hline
\end{tabular}


Table 13. Comparison of field density and laboratory compaction test of natural sub base material.

\begin{tabular}{|c|c|c|c|c|c|}
\hline \multirow{2}{*}{ Section } & \multirow{2}{*}{ Station } & \multicolumn{2}{|l|}{ Field test } & \multicolumn{2}{|c|}{ Laboratory test } \\
\hline & & Water content $(\%)$ & Dry density (g/cc) & OMC (\%) & MDD (g/cm3) \\
\hline \multirow{4}{*}{1} & $130+523$ & 15.2 & 1.94 & 18.8 & 1.60 \\
\hline & $130+570$ & 12 & 2.13 & 14.00 & 2.15 \\
\hline & $130+600$ & 13.5 & 1.95 & 13.44 & 1.86 \\
\hline & Average & 13.56 & 2.00 & 15.41 & 1.87 \\
\hline \multirow{4}{*}{2} & $102+030$ & 15.6 & 1.78 & 11.23 & 2.14 \\
\hline & $102+175$ & 11.23 & 2.14 & 12.00 & 1.79 \\
\hline & $102+187$ & 17.6 & 1.62 & 13.5 & 1.95 \\
\hline & Average & 14.81 & 1.87 & 12.24 & 1.96 \\
\hline \multirow{4}{*}{3} & $76+212$ & 23.83 & 1.85 & 11.69 & 2.18 \\
\hline & $76+457$ & 14.7 & 1.78 & 10.87 & 2.14 \\
\hline & $76+568$ & 19 & 1.68 & 15.7 & 1.83 \\
\hline & Average & 19.17 & 1.77 & 12.75 & 2.05 \\
\hline
\end{tabular}

Table 14. Comparison of field density and laboratory compaction test of base course.

\begin{tabular}{|c|c|c|c|c|c|}
\hline \multirow{2}{*}{ Section } & \multirow{2}{*}{ Station } & \multicolumn{2}{|l|}{ Field test } & \multicolumn{2}{|c|}{ Laboratory test } \\
\hline & & Water content (\%) & Dry density (g/cc) & OMC (\%) & MDD (g/cm3) \\
\hline \multirow{4}{*}{1} & $130+523$ & 3.05 & 1.91 & 2.20 & 2.26 \\
\hline & $130+570$ & 2.24 & 2.26 & 3.40 & 2.23 \\
\hline & $130+600$ & 3.05 & 2.23 & 5.00 & 2.15 \\
\hline & Average & 2.9 & 2.13 & 3.53 & 2.21 \\
\hline \multirow{4}{*}{2} & $102+030$ & 5.00 & 1.76 & 2.30 & 2.24 \\
\hline & $102+175$ & 4.4 & 1.85 & 7.40 & 2.10 \\
\hline & $102+187$ & 2.28 & 2.21 & 2.30 & 2.21 \\
\hline & Average & 3.89 & 1.94 & 4.00 & 2.18 \\
\hline \multirow{4}{*}{3} & $76+212$ & 2.28 & 2.21 & 2.40 & 2.19 \\
\hline & $76+457$ & 2.11 & 1.84 & 3.22 & 2.15 \\
\hline & $76+568$ & 3.12 & 1.78 & 3.52 & 2.08 \\
\hline & Average & 2.50 & 1.96 & 3.04 & 2.14 \\
\hline
\end{tabular}

\subsubsection{Atterberg's Limit}

From the laboratory results, the average liquid limit, Plasticity limit and Plasticity index of the subgrade and that of the selected subgrade fill material is summarized below

Table 15. Atterberg's Limits of pavement Materials.

\begin{tabular}{lllllll}
\hline \multirow{2}{*}{ Section } & Subgrade & \multicolumn{5}{c}{ Capping layer } \\
\cline { 2 - 7 } & LL (\%) & PL (\%) & PI (\%) & LL (\%) & PL (\%) & PI (\%) \\
\hline 1 & 56.67 & 33.00 & 23.67 & 42.9 & 30.10 & 12.77 \\
2 & 57.5 & 33.20 & 24.30 & 36.63 & 29.27 & 7.37 \\
3 & 57.13 & 35.50 & 21.63 & 37.93 & 30.83 & 7.10 \\
\hline
\end{tabular}

\subsubsection{Grain Size Analysis}

Comparing the laboratory test results for gradation with that of the specification for base course, the results showed that for all the three sections were within the limit. Besides the base course materials used for all the three sections of the road were similar based on the results of sieve analysis.

The comparison of the particle size distribution curve of the laboratory test results of all samples with the recommended particle size distribution for mechanically stable graded crushed stone used as base course material (GB1), while for granular sub base materials (GS) is based on ERA Pavement Design Manual [10].

It can be observed that the gradation of the base course at all the three sections, the gradation is within the recommended range. However, this recommended range will come to invalid if there is a possibility of moisture fluctuation because of poor drainage condition. Since this moisture fluctuation can be affected or washed out the fine ingredients of the base course material. The stability of coarse grained materials would depend on the grain-to-grain contact and are difficult to compact. Hence, such materials could not attain the required percent of field compaction because of low density. Moreover, such materials observed that it was displaced under load due to less supporting resistance. This could also be the reason for the rutting observed along the road as discussed above.

Furthermore, coarse-graded mixes can be excessively permeable to water due to their inherently larger void sizes. These larger void sizes increase the chances of their interconnection, which easily allow the water entry and infiltration and in turn, leads to higher permeability. This higher permeability resulted the underlain layers to moist that decrease its density.

From above figures, be observed that the gradation of the natural sub base at all the three sections. Gradation analysis was made for this layer at all sections and have different gradation curve with the section. However, it could be noted that section (1) and (2) lie within the recommended range 
provided at the project and ERA specifications. But the gradation curve of section 3 was not in the range of provided at the project and ERA specifications.

Based on, the gradation curve, it can be summarized that, the materials used at section (1) and (2) are relatively stable enough and have a good resistant to erosion. This can be compacted to a very dense condition which produce and develop good bearing capacity and shearing resistance. However, at section (3) the material used was course which is not having a good resistant to erosion stable enough.

Sieve analysis was also conducted for selected subgrade fill material and for the subgrade material. There was no recommended grading or plasticity criteria for these materials. However, according to the ERA Pavement Design manual, it is desirable to select reasonably homogeneous materials, since the overall pavement behavior is often enhanced the quality while proper selection of materials were show the least change in bearing capacity from dry to wet which is important.

\subsubsection{Soil Classification}

From AASHTO classification system for subgrade and capping layer based on the Table 15 The plasticity index value of subgrade material at all sections were found to have comprised A-7-6 which is greater than LL-30.

The plasticity index value of the selected subgrade materials or capping materials at (1) and (2) sections were classified as A-7-5, which is less than LL-30. Whereas, the plasticity index value of the selected subgrade materials or capping materials at section (3) was classified as A-7-6, which is greater than LL-30.

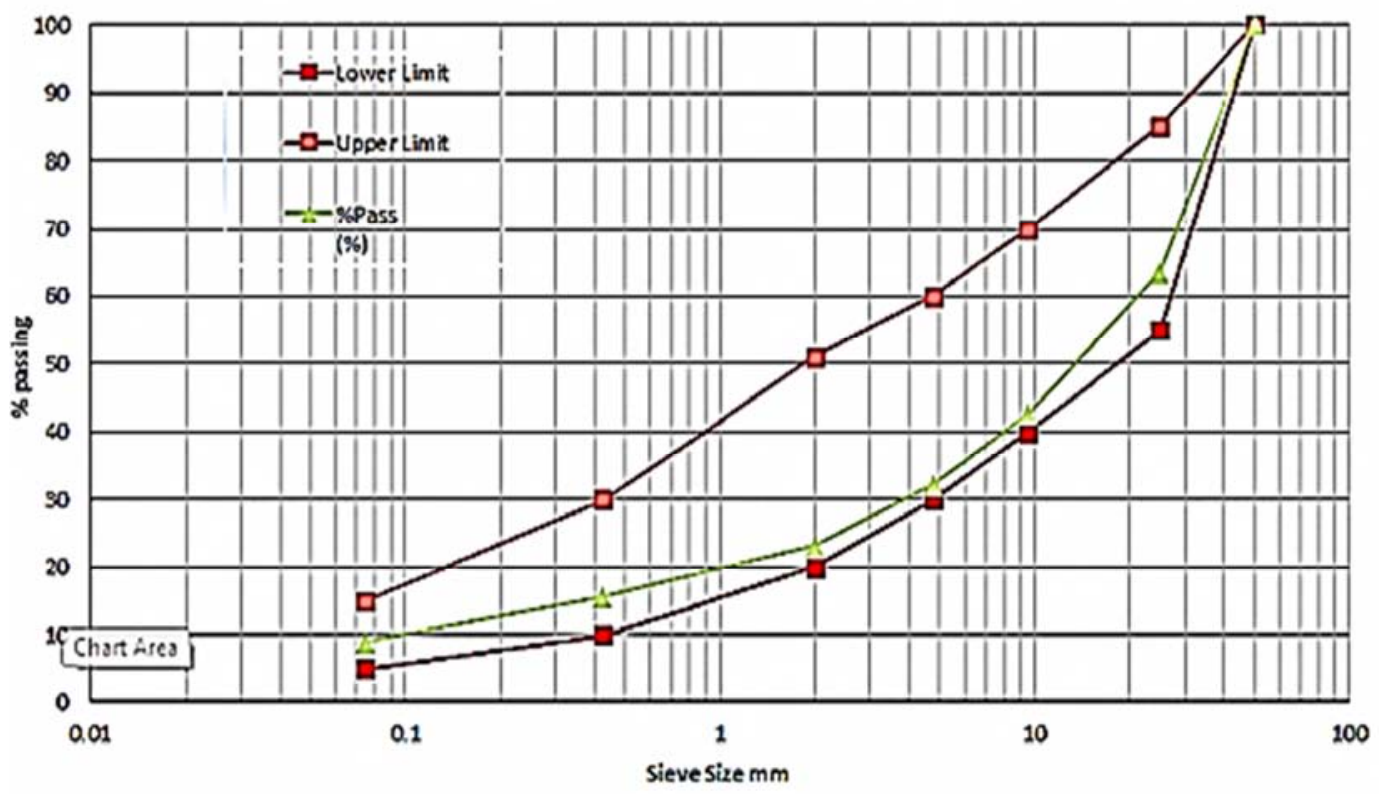

Figure 10. Comparison of base course material at section (1) with GB1.

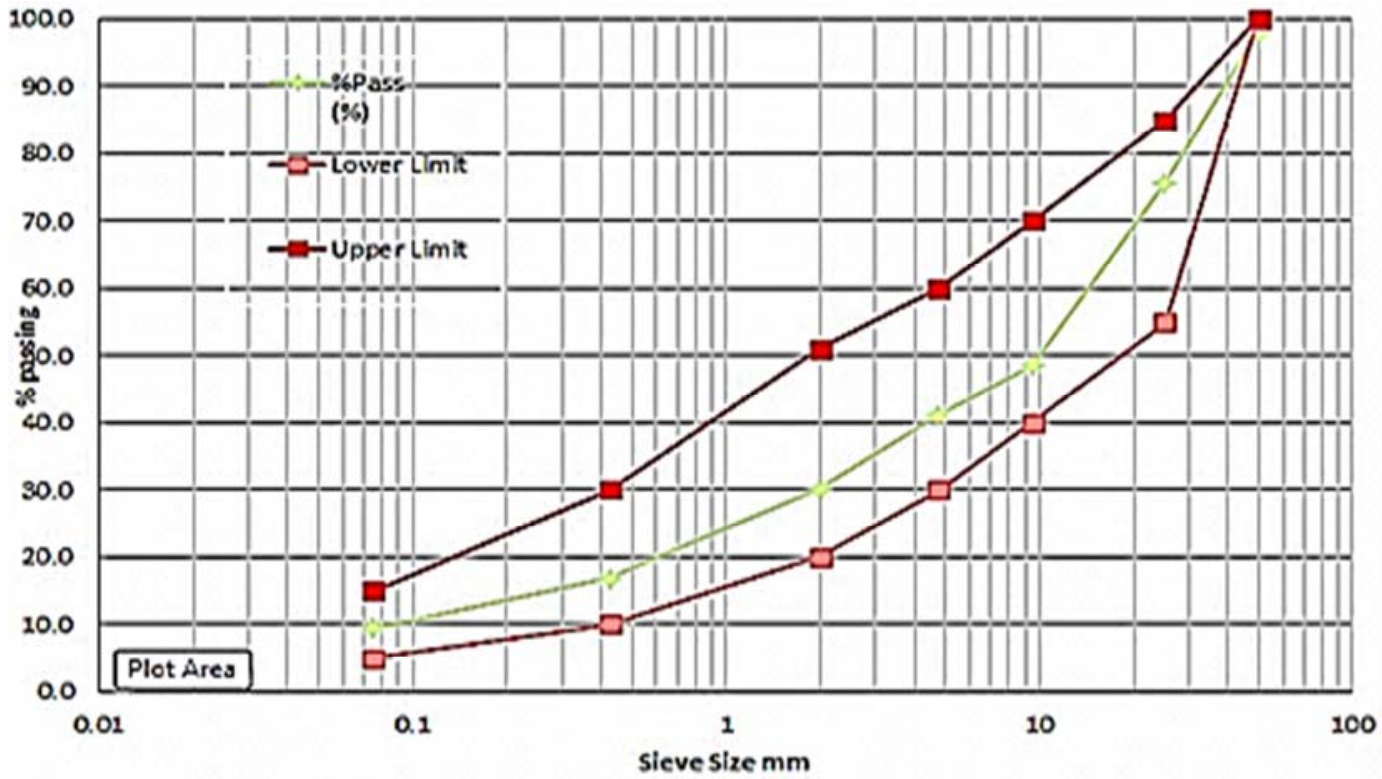

Figure 11. Comparison of base course material at section (2) with GB1. 


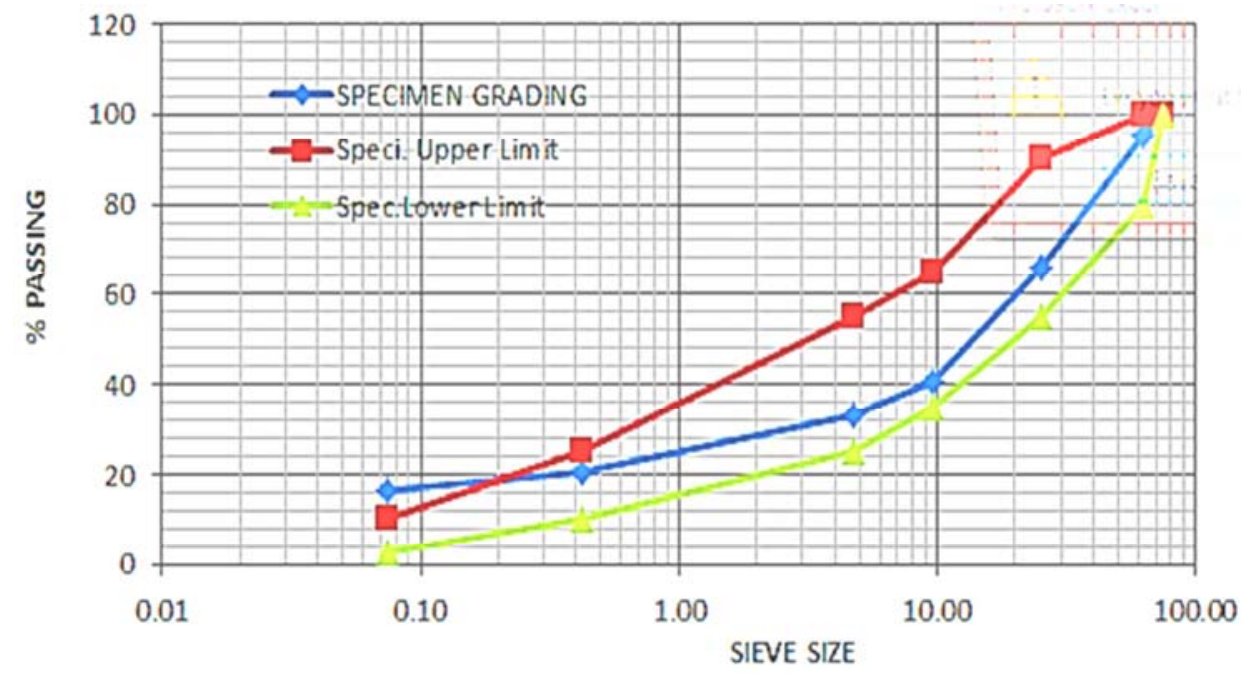

Figure 12. Comparison of base course material at section (3) with GB1.

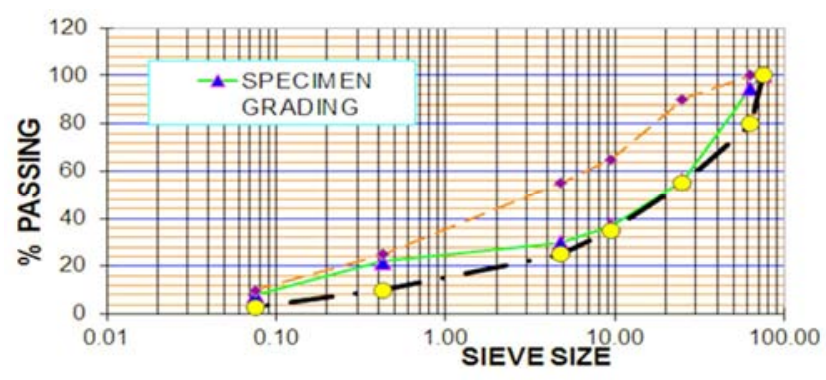

Figure 13. Comparison of natural sub base course material at section (1) with GS2.

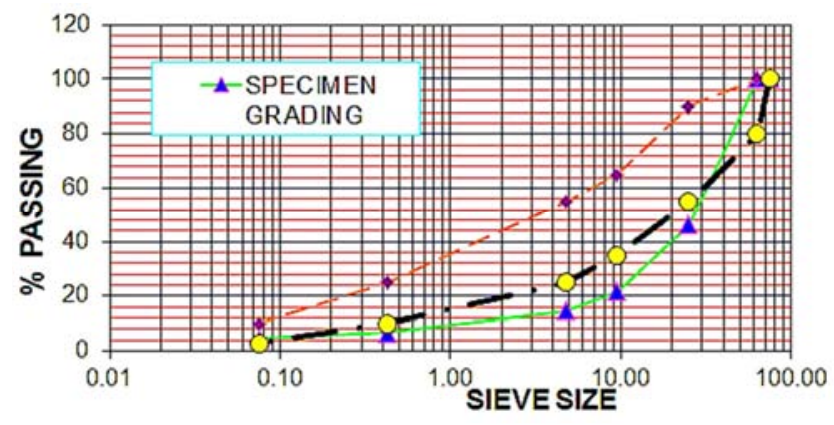

Figure 14. Comparison of natural sub base course material at section (2) with GS2.

\subsubsection{California Bearing Ratio (CBR) Test}

Based on the project specification and the recommendation given in ERA Pavement Design Manual volume I [9], for fresh, crushed rock (GB1), the CBR after soaking should be greater than 100 percent. As can be seen from the laboratory test results of this study area given in table 10, the CBR of the Crushed base course material used ranges from 105.33 to 124 averagely. Thus, from the point of CBR view the material is suitable to use as base course when compacted at its optimum moisture content and compacted to its maximum dry density. The CBR value at the field dry density is read from the laboratory dry density versus CBR curve. Example, the CBR value at the field dry density at section (1) is $130 \%>100 \%$, at section (2) is $115 \%>100$ and at section (3) is $100=100 \%$.

Considering natural subbase, the recommendation given in ERA Pavement Design Manual volume I [6] and the recommendation in the ERA project specification, for natural gravel (GS2), the CBR after soaking should be greater than 30 .

And the result obtained from the laboratory was greater than 30 ranging from 36.67 to 47.67 averagely at section (2) and (3). The CBR values obtained from the dry density versus CBR curve at section (1) is 29.17 , at section (2) is 48.00 and at section (3) are 37.00.

According to the specification given by ERA, Gravel or gravel-soil (GC) with CBR after soaking greater than 15 can be used as capping layer or selected subgrade fill material. The material used as selected subgrade fill material at section (1) is with an average CBR of 21.67 and at section (2) and section (3) is with an average CBR of 21.23 and 18.20 respectively. This indicates that, the selected material at the three sections used as capping layer is greater than the requirement given in the specification.

The average CBR obtained for Subgrade material when compacted at its optimum moisture content and maximum dry density obtained $5.22 \%$, at section (1), $6.47 \%$ at section (2) and $5.57 \%$ at section (3). The subgrade strength class for CBR range of 5-7 is S3, 8-14 is S4 and for 15-29 is S5. As most of the laboratory results lay on the range $5-7$, it can be classified as S3.

\subsection{Observations and Proposed Remedial Measures}

Based on the findings and observation of the study, at section (1) all the deterioration of the road could be related to Presence of water on or in the subgrade or sub base like percolation of water under the ground to the subgrade, infiltration of rain to the surface of the pavement during rainy season and the seepage of water at the interface of the of the pavements. As the water is ejected, the carries material was fine, thus resulting in progressive material deterioration and loss of support. 
Generally, the main cause of pavement deterioration of this section, as observed in the field, was due Presence of water on or in the subgrade or sub base along with heavy loads passing over the pavement surface and cracking the pavement. The Contractor must provide proper material for these voids beneath the pavement should be filled with high softening under sealing asphalt to prevent the intrusion of water in to the subgrade and sub base. The remedial measure of this highly deteriorated section (6) road should be reconstruction of layers up to subgrade level must be undertaken in order to repair. Additionally, in areas where cracks had already occurred, sealing of cracks with bitumen or any other suitable material to prevent further cracking and to minimize infiltration of water during rainy seasons.

Depending on the observation and finding of the road section at section (2) the deterioration of the road could be related to the insufficient thickness of the base course of the road section. At this section the speed breaker was provided, because of this the speed of the vehicles decrease around that, so that the pavement was consolidated or deflected under traffic in one or more of the underlying courses or displacement in the surface layer itself. The main cause of pavement deterioration of this section, as observed in the field, was due insufficient thickness of the base course. The remedial measures of this medium deterioration road section is reconstruction of base course and layers above it, by considering this speed breaker which increase the load by decreasing speed of the vehicles as per the requirement set in the ERA Standard Manual.

Addionally for the low deterioration of the road at section (3) the observed remedial measure is providing of proper side ditch which minimize the ejection of water in to the subgrade or sub base. The main cause of this road section deterioration, as observed in the field, was because of lack proper side ditch of the road. It was observed that the failure was within the edge of the road already deteriorated. But the results of the field test conducted during the field investigation showed that the dry density values of the subgrade were greater than the values stipulated in the specification and the CBR values found which is related to the field dry density for subgrade materials is less than the values stipulated in the ERA specification. So the Contractor should provide proper drainage facilities farther away from the toe of the shoulder and under the foundation of subgrade to prevent the ingression of water into the pavement layers

\section{Conclusion and Recommendation}

Depending on the observation and investigation of pavement condition survey, the field tests and laboratory tests the following conclusions are drawn.

1) The laboratory and field test results that had been obtained on the pavement materials used for the construction of the road section under the research discussed and compared with the requirements of the standard specification, which shows poor results at section (1) and relatively good results at section (2) and
(3).

2) The investigation have revealed that different type and degree of deteriorations observed on the pavement surface.

a High deteriorations observed at section (1), (pumping and potholes) type of deterioration are observed at this section.

b Medium deterioration is observed at section (2), (rutting and potholes) type of deterioration are observed at this section.

c Relatively low deterioration is noticed at section (3), (Edge cracking and Raveling) types of deterioration are observed at this section.

3) The major causes of deterioration of these flexible pavement along the Bako-Gedo road section are presence of water on or in the subgrade or sub base, lack of proper drainage at some points, lack of routine and timely maintenance on the sections of potholes and cracks, insufficient thickness, poor shoulder design, seepage of groundwater and infiltration of surface water into the pavement layer, poor field compaction, poor method of construction (i.e. construction of pavement layers during rainy season).

4) The thickness of the base course and sub-base course for traffic class $\mathrm{T}_{5}$ with ESAL of 3.0-6.0 million should be $20 \mathrm{~cm}$ and $25 \mathrm{~cm}$ respectively.

5) However, the average thickness of the existing road layer of the base course is $19.42 \mathrm{~cm}$ and that of the sub-base course is $22.67 \mathrm{~cm}$. Based on these values for base and sub-base course, the researcher concludes that the pavement would not be able to carry the existing traffic loading through-out its service life

6) CBR value related to the field dry density for base course is greater than the standard specification for low, medium and high deterioration road sections relative to the dry density obtained.

7) Averagely in areas of low and high deterioration road sections, the moisture contents obtained on the field for natural sub base and capping materials are much higher than the optimum moisture contents obtained in the laboratory test without considering given tolerances.

8) However, averagely in area of medium deterioration section the moisture content obtained on the field was relatively equal or less than the $\mathrm{OMC}$ obtained in laboratory by considering given tolerance.

9) The average of the observed CBR values of the natural sub bases is good (greater than 30) for section (2) and (3) according to standard specification. But at section (1) the CBR value of natural sub base is less than 30 (minimum of the specification). Therefore, the deterioration frequently observed on the road surface is significantly influenced by natural sub base strength. Related to the field dry density the value of the CBR, for capping layer materials are good or greater than the minimum requirement of standard specification at all sections. 


\section{References}

[1] Ethiopian Roads Authority. Project Design Review, Gedo-Nekemte Road Upgrading Project Draft Submission. 2007.

[2] Ethiopian Roads Authority. Road Sector Development: 1997-2007. Final Draft. Addis Ababa Ethiopia.1996.

[3] Ethiopian Roads Authority Standard Manuals. Pavement Rehabilitation and Asphalt Overlay Manual. 2002.

[4] ERA. Ethiopian Roads Authority Standard Manuals. Pavement Design Manual: Flexible Pavements and Gravel Roads, Volume I. 2002.

[5] Keith RK. Northwest pavement Management systems users
Group and Washington State Department of Transportation. March 1992.

[6] Ethiopian Roads Authority Standard Specification.2002.

[7] Ethiopian Roads Authority Standard Manuals. Gedo-Nekemte Road Upgrading Project.2009.

[8] Chen FH. Foundations on Expansive Soils. New York Elsevier Science Publisher. 1998.

[9] P. Croney and D. Croney, The Design and Performance of Road Pavements. New York City: McGraw-Hill Professional, 1998.

[10] W. Paterson, "Road Deterioration and Maintenance Effects: Models for planning and Management," Baltimore: The John Hopkins University press, 1987. 